\title{
Polymerization Induced Phase Separation in Composite Latex Particles During Seeded Emulsion Polymerization
}

\author{
Pei Zhang a,1, Donald C. Sundberga and John G. Tsavalasa, ${ }^{\mathrm{a}, \mathrm{b}^{*}}$
}

a. Nanostructured Polymers Research Center, Materials Science Program, University of New Hampshire, Durham, New Hampshire 03824 USA

b. Department of Chemistry, University of New Hampshire, Durham, New Hampshire 03824 USA

1. Present address: Arkema Changshu Research \& Development Center, China

* Corresponding author: John G. Tsavalas, john.tsavalas@unh.edu

Supporting Information 


\section{Estimation of solubility parameter}

To calculate $\Delta \mathrm{G}_{\mathrm{mix}}$ of all reaction systems in the work, solubility parameters were initially required to obtain interaction parameters. Values of the solubility parameters were first obtained from the Coleman - Solubility Parameters calculator ${ }^{1}$. It was assumed that the data set for a number of polymers should follow a trend due to similarity among the polymer structures. However, the value for PS in this software is 9.5 and much higher than the more hydrophilic PBA, which did not seem reasonable. Predicted values from Coleman calculation software are listed below; values reported in other references ${ }^{2-5}$ are also summarized in Table S1.

\begin{tabular}{|c|c|c|c|c|c|c|c|c|c|c|c|c|c|}
\hline Monomer unit & $\begin{array}{c}\delta,\left(\mathrm{cal} / \mathrm{cm}^{3}\right)^{0.5} \\
{[1]}\end{array}$ & small [2] & Hoy [2] & $\begin{array}{c}\text { HOFTYZER } \\
{[2]}\end{array}$ & $\begin{array}{c}\text { cohesive } \\
\text { energy } \\
\text { group [2] }\end{array}$ & $\begin{array}{c}\text { Askadskii } \\
\text { [2] }\end{array}$ & $\begin{array}{c}\text { Swelling } \\
\text { [2] }\end{array}$ & $\begin{array}{c}\text { Intrinsic } \\
\text { [2] }\end{array}$ & $\begin{array}{c}\mathrm{C}_{\mathrm{sat}}, \mathrm{m} / \mathrm{L} \\
{[3]}\end{array}$ & $\begin{array}{c}\text { solubility, } \\
\text { wt\% [4] }\end{array}$ & $\begin{array}{l}\text { solubility, } \\
\text { mol\% [4] }\end{array}$ & $\begin{array}{c}\text { molarity } \\
{[4]}\end{array}$ & $\begin{array}{l}\mathrm{g}(\mathrm{H} 2 \mathrm{O}) / \text { struc } \\
\text { ture unit[5] }\end{array}$ \\
\hline styrene & 9.1 & 9.0 & 9.0 & 9.5 & 8.9 & 9.1 & 9.1 & 8.6 & 0.004262 & 0.237 & 0.041 & 0.0249 & 0.00086 \\
\hline butadiane & 8.1 & 8.1 & 8.3 & 8.4 & 7.9 & & 8.5 & & 0.003885 & & & & 0.00002 \\
\hline butyl acrylate & 8.9 & 9.1 & 9.1 & 10.0 & 8.9 & & 8.8 & 8.8 & 0.00646 & 0.338 & 0.0476 & 0.0289 & 0.02809 \\
\hline n-butly methacrylate & 8.7 & 8.7 & 8.7 & 9.0 & 8.7 & 8.8 & 8.8 & & 0.002497 & & & & 0.02532 \\
\hline ethyl acrylate & 9.3 & 9.1 & 9.2 & 8.9 & 9.2 & 9.3 & 9.4 & 9.4 & 0.149834 & 2.13 & 0.389 & 0.237 & 0.03596 \\
\hline eyhyl methacrylate & 8.9 & 8.2 & 8.3 & 8.4 & 8.6 & 9.1 & 8.9 & & & & & & 0.03154 \\
\hline 2-ethylhexyl acrylate & 8.5 & & & & & & & & 0 & 0.0164 & 0.0016 & 0.000971 & 0.01953 \\
\hline hexyl methacrylate & 8.5 & & & & & & & & & & & & 0.02115 \\
\hline Methyl acrylate & 9.6 & 9.2 & 9.3 & 8.9 & 9.4 & 9.6 & 10.1 & 10.1 & 0.610434 & 5.53 & 1.21 & 0.741 & 0.04182 \\
\hline methyl methacrylate & 9.1 & 8.7 & 8.8 & 8.9 & 10.0 & 9.3 & 9.5 & 9.4 & 0.150944 & 2.25 & 0.419 & 0.256 & 0.03596 \\
\hline
\end{tabular}

Table S1. Solubility parameters collected from different resources

One issue with these data sets is that the experimental results were obtained by different experimental techniques. Therefore, we plotted the Coleman $\delta$ values against monomer solubility in water $\left(\mathrm{Schork}^{4}\right), \mathrm{C}_{\text {sat }}$ (solubility of monomer in water, from UNHLATEX KMORPH $)^{3}$, molarity (from Schork ${ }^{4}$ ) or per-structure water content ${ }^{5}$, trying to find any consistency in the trends of data. However, no consistency could be found among those data sets.

The solubility parameter is a numerical value that indicates the relative solvency behavior of a specific solvent. It is derived from the cohesive energy density of the solvent, which in turn is derived from the heat of vaporization. In solubility theories, three types of polar interactions are 
most commonly used: dispersion forces, polar forces, and hydrogen bonding forces. The connection among these forces is usually written as: $\delta \mathrm{t}^{2}=\delta \mathrm{d}^{2}+\delta \mathrm{p}^{2}+\delta \mathrm{h}^{2}$

where

$\delta \mathrm{t}^{2}=$ Total Hildebrand parameter

$\delta \mathrm{d}^{2}=$ dispersion component

$\delta \mathrm{p}^{2}=$ polar component

$\delta \mathrm{h}^{2}=$ hydrogen bonding component

This suggests that we look at the connection between different chemical structures. For example, for methyl acrylate which has an acrylic (ester) group but no methyl side group, it should have a higher $\delta \mathrm{h}^{2}$ than MMA. For styrene, there should be no hydrogen bonding effect so its $\delta \mathrm{h}^{2}=0$. Also, PMMA is more polar than PS so it should have higher $\delta \mathrm{p}^{2}$ than PS does. This could be a way to look at those data sets and develop a reasonable rule to judge the quality of the data. It is also demonstrated in references that, although the solubility theory is well developed, and the parameter can be obtained by several calculation or experimental methods, the accuracy of those values is limited. Hence, our goal was not to find the "absolute correct" values but instead, to establish a data set which correlate well with a single, physical parameter so it can be applied for further calculations.

Monomer solubilities in water $\left(\mathrm{C}_{\mathrm{sat}}\right)$ values from UNHLATEX KMORPH ${ }^{3}$ were obtained from previous research in our group which we have more confidence in their reliability. Hence, this set of data was chosen to compare with the water saturation molarity values reported by Schork $^{4}$ as shown in Table S2. 


\begin{tabular}{|l|r|r|}
\hline monomer & molarity & Csat mol/L \\
\hline Methyl acrylate & 0.741 & 0.610434 \\
\hline methyl methacrylate & 0.256 & 0.150944 \\
\hline ethyl acrylate & 0.237 & 0.149834 \\
\hline butyl acrylate & 0.0289 & 0.00646 \\
\hline styrene & 0.0245 & 0.004262 \\
\hline butadiane & & 0.003885 \\
\hline n-butly methacrylate & & 0.002497 \\
\hline 2-ethylhexyl acrylate & 0.000971 & 0.00054 \\
\hline
\end{tabular}

Table S2. Comparison between Csat values from our group and molarity values reported by Schork et al.

It can be noticed that these two date sets are close to each other and varying in the same trend except the two points for styrene and BA. Despite of this difference, the other values agreed with each other quite well. For example, MA has the highest value which is reasonable due to its hydrophilic chemical structure. MMA/EA and BA/Styrene/nBMA can be treated as two different groups based on their data range; while 2-EHA has the smallest value. One thing should be noticed is that $\mathrm{C}_{\text {sat }}$ of $\mathrm{Bd}$ seems incorrect as it should be smaller than the value of nBMA due to its less polar structure. As mentioned above, from solubility parameter theory, the solubility should relate to the chemical structure. If we look at those groups, it is found that: MA has the lowest number of $\mathrm{C}$ in structure as 4; MMA and EA have the same number of $\mathrm{C}$ as 5; BA, Styrene and nBMA have close number of $\mathrm{C}$ as 7,8 and 8; 2-EHA, on the hand, has the largest number of $\mathrm{C}$ as 11 . This suggests that one approach for predicting solubility parameters of various polymers could be determining the trend of solubility parameters vs. number of $\mathrm{C}$ in their chemical structures.

We checked all data sets from references based on the tendency described above. It was found that most of the data sets have several points that do not follow the trend with Csat. 
Nevertheless, the Coleman calculator can provide data points for various polymers and most of its data points have reasonable values. Hence, we decided to use Coleman software to obtain solubility parameters for all the polymer structures we needed and adjust their results based on their trend with Csat.

\begin{tabular}{|c|c|c|c|c|c|c|c|c|c|c|c|c|c|c|c|c|}
\hline Monomer unit & $\begin{array}{c}\delta,\left(\mathrm{cal} / \mathrm{cm}^{3}\right)^{0.5} \\
{[1]}\end{array}$ & small [2] & Hoy [2] & $\begin{array}{c}\text { HOFTYZER } \\
{[2]}\end{array}$ & $\begin{array}{c}\text { cohesive } \\
\text { energy } \\
\text { group [2] }\end{array}$ & $\begin{array}{c}\text { Askadskii } \\
{[2]}\end{array}$ & $\begin{array}{c}\text { Swelling } \\
\text { [2] }\end{array}$ & $\begin{array}{c}\text { Intrinsic } \\
{[2]}\end{array}$ & $\begin{array}{c}\mathrm{C}_{\text {sat }}, \mathrm{m} / \mathrm{L} \\
{[3]}\end{array}$ & $\begin{array}{c}\text { solubility, } \\
\text { wt\% [4] }\end{array}$ & $\begin{array}{l}\text { solubility, } \\
\text { mol\% [4] }\end{array}$ & $\begin{array}{c}\text { molarity } \\
{[4]}\end{array}$ & $\begin{array}{c}\mathrm{g}(\mathrm{H} 2 \mathrm{O}) / \text { struc } \\
\text { ture unit[5] }\end{array}$ & total \#C & $\begin{array}{l}\text { \#C in } \\
\text { acrylic } \\
\text { group }\end{array}$ & Calculated $\delta$ \\
\hline styrene & 9.1 & 9.0 & 9.0 & 9.5 & 8.9 & 9.1 & 9.1 & 8.6 & 0.004262 & 0.237 & 0.041 & 0.0249 & 0.00086 & 8 & 0 & 8.8 \\
\hline butadiane & 8.1 & 8.1 & 8.3 & 8.4 & 7.9 & & 8.5 & & 0.003885 & & & & 0.00002 & 4 & 0 & \\
\hline butyl acrylate & 8.9 & 9.1 & 9.1 & 10.0 & 8.9 & & 8.8 & 8.8 & 0.00646 & 0.338 & 0.0476 & 0.0289 & 0.02809 & 7 & 4 & 9 \\
\hline n-butly methacrylate & 8.7 & 8.7 & 8.7 & 9.0 & 8.7 & 8.8 & 8.8 & & 0.002497 & & & & 0.02532 & 8 & 4 & 8.7 \\
\hline ethyl acrylate & 9.3 & 9.1 & 9.2 & 8.9 & 9.2 & 9.3 & 9.4 & 9.4 & 0.149834 & 2.13 & 0.389 & 0.237 & 0.03596 & 5 & 2 & 9.3 \\
\hline eyhyl methacrylate & 8.9 & 8.2 & 8.3 & 8.4 & 8.6 & 9.1 & 8.9 & & & & & & 0.03154 & 6 & 2 & 8.9 \\
\hline 2-ethylhexyl acrylate & 8.5 & & & & & & & & 0 & 0.0164 & 0.0016 & 0.000971 & 0.01953 & 11 & 8 & 8.4 \\
\hline hexyl methacrylate & 8.5 & & & & & & & & & & & & 0.02115 & 10 & 6 & 8.5 \\
\hline Methyl acrylate & 9.6 & 9.2 & 9.3 & 8.9 & 9.4 & 9.6 & 10.1 & 10.1 & 0.610434 & 5.53 & 1.21 & 0.741 & 0.04182 & 4 & 1 & 9.5 \\
\hline methyl methacrylate & 9.1 & 8.7 & 8.8 & 8.9 & 10.0 & 9.3 & 9.5 & 9.4 & 0.150944 & 2.25 & 0.419 & 0.256 & 0.03596 & 5 & 1 & 9.1 \\
\hline
\end{tabular}

Table S3. All data points from references and calculated values from trend line in Figure A3

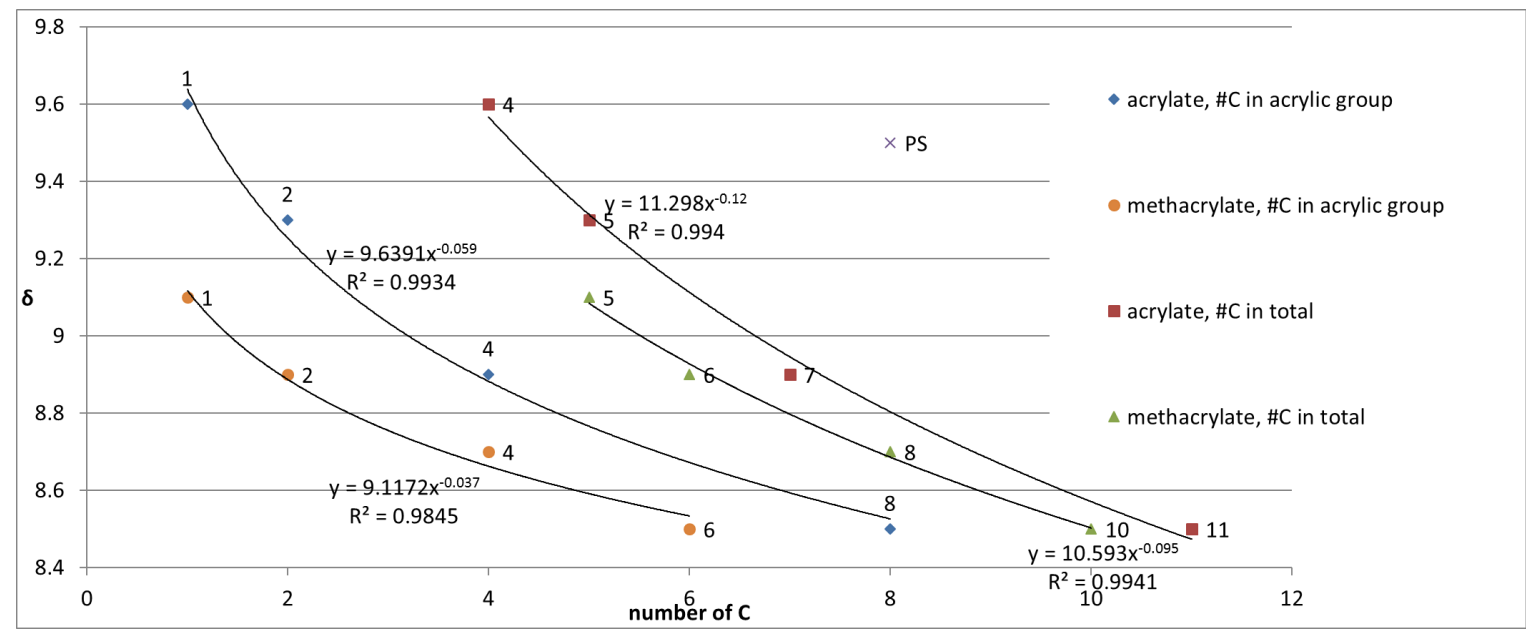

Figure S1. Solubility parameters calculated from Coleman software for different polyacrylates and polymethacrylates vs. number of $\mathrm{C}$ in acrylic (ester) group or total $\mathrm{C}$ in monomer unit

Figure S1 is a plot of the number of carbons in whole structure/in acrylic (ester) group vs. Coleman solubility parameter $(\delta)$ of methacrylates and acrylates. It is observed that:

1. For acrylates, $\delta$ decrease when the $\#$ of $C$ in acrylic group increase. For example, MA has one $\mathrm{C}$ in acrylic group while EA has two and EA has a smaller $\delta$ due to less polar effect from the 
structure.

2. For methacrylates, $\delta$ also decrease when the \# of $\mathrm{C}$ in acrylic group increase. The same reason as in acrylates group.

3. When having the same \# of $\mathrm{C}$ in acrylic group but different in side group, eg. MA and MMA, $\delta$ of MA is higher than MMA because MMA has one extra $\mathrm{CH}_{3}$ side group which makes it more hydrophobic than MA.

4. The variation tendencies of $\delta$ between acrylates and methacrylates are the same when compared their total \#C.

Thus, for both acrylates and methacrylates, $\delta$ decreases with either total $\mathrm{C}$ number or number of $\mathrm{C}$ in acrylic group in a nearly linear manner. This change is reasonable based on solubility theory. The effects from polar and hydrogen bonding components in the total $\delta$ should lessen with increased hydrophobicity, which can, in turn, be raised with more $\mathrm{C}$ in the overall structure. Now when the data points are plotted against total $\mathrm{C}$ number, their trend-lines have a higher $\mathrm{R}^{2}$. Therefore, we decided to use these two trend-lines to predict $\delta$ values for any other acylates/methacrylates which are not available in the Coleman software. All calculated values are listed in Table S3.

For polystyrene, the Coleman software provided 9.5 which is even higher than the one of PMMA. By comparing the Csat and molarity of monomers, we believe that polystyrene should have a value close to PBA and PnBMA. PBA unit has $7 \mathrm{C}$ in total and it also has hydrogen bonding effect while styrene unit has $8 \mathrm{C}$ in total and no hydrogen bonding effect. So, PS should have a smaller value than PBA. PnBMA unit also has $8 \mathrm{C}$ in total and by looking at other data sets, $\delta$ of 
PnBMA is always lower than $\delta$ of PS. Therefore, we believe PS should have a value between PBA (8.9) and PnBMA (8.7) and therefore set it as 8.8.

If we use PS 8.8 and PMMA 9.1 to calculate interaction parameter $\chi$, the result is 0.012 . As reported in reference, for PS-PMMA di-block copolymers, the experiment values are 0.0326 , $0.028,0.03$ and 0.0374 by different research groups ${ }^{6}$, which are higher than our result. It is possible that the different values are due to structure features of a di-block polymer versus a random polymer. But as mentioned in the beginning, our purpose here is to obtain a reasonable set of well correlated data for future calculation.

\section{Determination of interaction parameter, $\chi_{12}$}

The value of the Flory-Huggins interaction parameter $\chi_{12}$ can be determined from solubility parameters as follows, $\chi_{12}=\frac{V}{R T}(\delta 1-\delta 2)^{2}$

where $\delta i$ is the solubility parameter for polymer i and $\mathrm{V}$ is molar volume of a monomer unit. The units of $\delta 1$ used in this equation are $\mathrm{cal} / \mathrm{cm}^{3}$, so R used here is $1.98 \mathrm{cal} / \mathrm{K} / \mathrm{mol}$.

\section{References}

(1) Coleman, M.M.; Painter, P.C. Miscible polymer blends: Background and guide for calculations and design; DEStech Publications, Inc, 2006.

(2) Barton, A.F. CRC handbook of solubility parameters and other cohesion parameters; Routledge, 2017.

(3) University of New Hampshire Latex Industrial Consortium, UNHLATEX ${ }^{\circledR}$ KMORPH Version 6.0 User Manual, 2017.

(4) Chai, X.S.; Schork, F.J.; DeCinque, A; Wilson, K. Measurement of the Solubilities of Vinylic Monomers in Water. Ind. Eng. Chem. Res. 2005, 44, 5256.

(5) Van Krevelen, D.W.; Te Nijenhuis, K. Polymer properties. Properties of Polymers 3. 1990.

(6) Schubert, D.W.; Stamm, M. Influence of chain length on the interface width of an incompatible polymer blend. Europhys. Lett. 2007, 35, 419. 